\title{
The Critical Adiabatic Linear Tapered Waveguide Combined with a Multimode Waveguide Coupler on an SOI Chip
}

\author{
C. L. Chiu $(\mathbb{D}$ and Yen-Hsun Liao \\ Department of Electronic Engineering, National Kaohsiung University of Science and Technology, No. 415 Jiangong Road, \\ Kaohsiung 807, Taiwan \\ Correspondence should be addressed to C. L. Chiu; clchiu@nkust.edu.tw
}

Received 10 August 2019; Revised 12 October 2019; Accepted 17 October 2019; Published 11 November 2019

Guest Editor: Cheng-Mu Tsai

Copyright (c) 2019 C. L. Chiu and Yen-Hsun Liao. This is an open access article distributed under the Creative Commons Attribution License, which permits unrestricted use, distribution, and reproduction in any medium, provided the original work is properly cited.

\begin{abstract}
A multimode waveguide interference (MMI) coupler is combined with a critical linear tapered waveguide on a silicon-oninsulator (SOI) chip. When the $\mathrm{TE}_{0}$ mode is a critical adiabatic mode conversion from a single-mode waveguide to an extreme linear tapered waveguide combined with an MMI, this linear tapered waveguide is achieved to the maximum divergence angle (i.e., the shortest length). The maximum divergence angle is expressed by $\theta \leq 2 \tan ^{-1}\left[\left(0.35 W_{\mathrm{mmi}}-W_{\mathrm{s}}\right) /\left(0.172 L_{\mathrm{mmi}}\right)\right]$ under a $1 \times 1$ MMI combined with this critical linear tapered waveguide. The expression formula is demonstrated by three different widths of a $1 \times 1 \mathrm{MMI}$ of $4 \mu \mathrm{m} / 8 \mu \mathrm{m} / 12 \mu \mathrm{m}$ combined with the critical linear tapered waveguide. So, the maximum divergence angle is obtained at $\theta=16^{\circ} / 14^{\circ} / 8^{\circ}$, with respect to this linear tapered waveguide loss of $0.022 \mathrm{~dB} / 0.172 \mathrm{~dB} / 0.158 \mathrm{~dB}$, and this linear tapper length is reduced by $93.7 \% / 92.9 \% / 87.5 \%$ than the divergence angle $\theta=1^{\circ}$. The output power of a $1 \times 1 \mathrm{MMI}$ combined with a critical linear tapered waveguide is enhanced at least 1.5 times under 0.95 above condition.
\end{abstract}

\section{Introduction}

In the last few years, there have been numerous advances in silicon photonics. Photonic devices on a silicon-on-insulator (SOI) chip with high-index contrast have high integration density. The main advantage of the optoelectronic component on an SOI structure is its good compatibilities [1]. Couplers and power dividers in photonic integrated circuits (PICs) are often implemented with multimode interference couplers (MMIs) for easy fabrication and broad bandwidth. The SOI platform is an area of interest in integrated optics at present and enables a size reduction of PICs. Therefore, their CMOS compatibility can provide optoelectronic integration on a chip in future applications [2]. MMIs are based on the expansion of a fundamental mode of the access waveguide into multiple modes of the wider width of a multimode waveguide, which interfere as they propagate and form images of the excitation. Ridge waveguides are widely used in SOI, as they offer a single-mode behaviour at micrometre scale [3]. MMIs depend on multimode waveguides, utilizing bends for higher order mode filtering. They generally propagate well, and the weak lateral confinement of narrow ridge waveguides makes it difficult to achieve high-performance devices [4].

In 2010, Thomson et al. proposed a method to achieve a reduction of optical loss through the use of linear tapers with input and output ports. The taper loss is reduced to below $1 \mathrm{~dB}$ without affecting static extinction [5]. In 2012, Sheng et al. proposed the compact and low-loss MMI coupler fabricated with CMOS technology. This tapered waveguide with a divergence angle $\theta$ of $1^{\circ}$ combined with an MMI is fabricated on SOI with $0.13 \mu \mathrm{m}$ CMOS technology to obtain an excess loss of only $0.06 \mathrm{~dB}$ [6]. Researchers have adopted the widest and longest linear tapered waveguide to be combined with an MMI coupler on an SOI chip in recent devices. This critical problem will increase manufacturing costs, so it is necessary to design an adiabatic tapered waveguide.

The losses inherent to a mode propagating waveguide must be reduced on the cross-sectional boundary between the single-mode waveguide and multimode waveguide. Because a tapered waveguide can change the spot size and 
the shape of the optical mode to achieve high coupling efficiency in the cross section boundary [7], a tapered waveguide is necessary to achieve an adiabatic state [7-10]. That is, as the $\mathrm{TE}_{0}$ mode from a single-mode waveguide is transmitted to the tapered waveguide, the other higher order TE modes are reduced to excited modes [11-17].

In this article, we propose an expression formula to design a terminal linear tapered waveguide to enhance the coupling efficiency output power of an MMI coupler to two times above. The low-loss and maximum divergence angle linear tapered waveguide combined with a $1 \times 1 \mathrm{MMI}$ on an SOI chip is achieved to an output power of above 0.95 . The $\mathrm{TE}_{0}$ mode component ratio is necessary to be above $97.85 \%$ in order to achieve a critical adiabatic mode conversion.

\section{Device Structure}

The cross section of an SOI structure is shown in Figure 1. The thickness of the upper cladding $\mathrm{SiO}_{2}$ layer is $2 \mu \mathrm{m}$, and the Si layer is deposited at a height $h_{\text {co }}$ of $220 \mathrm{~nm}$ on a $2-\mu \mathrm{m}-$ thick buried oxide layer based on a $\mathrm{Si}$ substrate. The refractive indices of $\mathrm{Si}$ and $\mathrm{SiO}_{2}$ are $n_{\mathrm{Si}}=3.475$ and $n_{\mathrm{SiO} 2}=1.444$, respectively. The ridge waveguide has a depth of $2.22 \mu \mathrm{m}$, and the effective core refractive index $n_{\mathrm{r}}$ of 2.509 and cladding refractive index $n_{\mathrm{c}}$ of 2.372 at an operating wavelength $\lambda_{0}$ of $1550 \mathrm{~nm}$ in a slab waveguide [18].

MMI couplers have higher tolerance to dimensional changes in the fabrication process, an easier fabrication process than other couplers, lower inherent loss, large optical bandwidth, and low polarization dependence [19]. Multimode waveguides excite numerous modes depending on their width and depth. The width of a fixed step index multimode waveguide $W_{\mathrm{mmi}}$ is generally referred to as $N \times M \mathrm{MMI}$ coupler, where $N$ and $M$ indicate input and output ports. For high-index contrast waveguides, the penetration depth is very small so that $W_{\mathrm{e}} \approx W_{\mathrm{mmi}}$. However, the effective width $W_{\mathrm{e}}$ can correspond to the fundamental mode [18]:

$$
W_{\mathrm{e}}=W_{\mathrm{mmi}}+\left(\frac{\lambda_{0}}{\pi}\right)\left(\frac{n_{\mathrm{c}}}{n_{\mathrm{r}}}\right)^{2 \sigma}\left(n_{\mathrm{r}}^{2}-n_{\mathrm{c}}^{2}\right)^{-1 / 2},
$$

where $\lambda_{0}$ is an operating wavelength and $n_{\mathrm{r}}$ and $n_{\mathrm{c}}$ are the effective core and cladding refractive indices, respectively. The term $\sigma=0$ represents transverse electric (TE) mode and $\sigma=1$ is for transverse magnetic (TM) mode. $L_{\pi}$ is defined as the beat length of the two lowest order modes [19], as follows:

$$
L_{\pi}=\frac{\pi}{\beta_{0}-\beta_{1}} \cong \frac{4 n_{\mathrm{r}} W_{\mathrm{e}}^{2}}{3 \lambda_{0}},
$$

where $\beta_{0}$ and $\beta_{1}$ are individual zero-order and first-order propagation constant. The term $n_{\mathrm{r}}$ is the effective core refractive index of the slab waveguide from which a $1 \times 1 \mathrm{MMI}$ coupler is made. $W_{\mathrm{e}}$ is the effective width of the MMI waveguide, and $L_{\mathrm{mmi}}$ is the exact imaging length [20]:

$$
L_{\mathrm{mmi}}=\frac{3}{4} L_{\pi}
$$

The geometric shape of a basic $1 \times 1$ MMI coupler is shown in Figure 2(a). A single-mode ridge waveguide with width $W_{\mathrm{s}}$ of $0.4 \mu \mathrm{m}$, length $L_{\mathrm{s}}$ of $100 \mu \mathrm{m}$, and a depth of $2.22 \mu \mathrm{m}$ is calculated by the effective core refractive index $n_{\mathrm{r}}$ of 2.509 and the effective cladding refractive index $n_{c}$ of 2.372 [17]. An MMI width adapted to 10/20/30 times the single waveguide of $0.4 \mathrm{um}$ as an inspecting standard case. The widths of a $1 \times 1 \mathrm{MMI} W_{\mathrm{mmi}}$ are choice of $4 \mu \mathrm{m} / 8 \mu \mathrm{m} /$ $12 \mu \mathrm{m}$ respect to the beat lengths $L_{\pi}$ of $45.7 \mu \mathrm{m} / 159.8 \mu \mathrm{m} /$ $342.9 \mu \mathrm{m}$ from equation (2) at an operating wavelength of $\lambda_{0}=1550 \mathrm{~nm}$. Therefore, the exact image length of a $1 \times 1$ MMI $L_{\mathrm{mmi}}$ achieves $34.3 \mu \mathrm{m} / 119.8 \mu \mathrm{m} / 257.1 \mu \mathrm{m}$, respectively, by equation (3). A linear tapered waveguide combined with a $1 \times 1 \mathrm{MMI}$ is shown in Figure $2(\mathrm{~b})$. The input/output port of this $1 \times 1 \mathrm{MMI}$ is a single-mode waveguide linked with a linear tapered waveguide. $W_{\mathrm{t}}$ is the width and $L_{\mathrm{t}}$ the length of a linear tapered waveguide. The divergence angle $\theta$ of a linear tapered waveguide is a taper angle. A half angle of the divergence angle is defined by the following equation:

$$
\tan \left(\frac{\theta}{2}\right)=\frac{W_{\mathrm{t}}-W_{\mathrm{s}}}{2 L_{\mathrm{t}}}
$$

The simulation analysis utilizes the film mode matching method (FMM) solver in FIMMWAVE software [21,22]. The output power of a basic $1 \times 1 \mathrm{MMI}$ with the exact length $L_{\mathrm{mmi}}$ is shown in Figure 3. Figure 3(a) is the length $L_{\mathrm{mmi}}$ of a $1 \times 1 \mathrm{MMI}$ scanning the range from $26.7 \mu \mathrm{m}$ to $30.7 \mu \mathrm{m}$ with a step of $0.2 \mu \mathrm{m}$ at MMI width $W_{\mathrm{mmi}}=4 \mu \mathrm{m}$. The maximum output power is 0.62 at $L_{\mathrm{mmi}}=28.7 \mu \mathrm{m}$. Figure $3(\mathrm{~b})$ is the length $L_{\mathrm{mmi}}$ of a $1 \times 1$ MMI scanning the range from $111.0 \mu \mathrm{m}$ to $115.0 \mu \mathrm{m}$ with a step of $0.2 \mu \mathrm{m}$ at MMI width $W_{\mathrm{mmi}}=8 \mu \mathrm{m}$. Here, the maximum output power is 0.51 at $L_{\mathrm{mmi}}=113.0 \mu \mathrm{m}$. Figure 3(c) is the same method at MMI width $W_{\mathrm{mmi}}=12 \mu \mathrm{m}$ for $L_{\mathrm{mmi}}$ scanning the range from $255.2 \mu \mathrm{m}$ to $259.2 \mu \mathrm{m}$. Maximum output power is 0.41 at $L_{\mathrm{mmi}}=257.2 \mu \mathrm{m}$. Accordingly, $L_{\mathrm{mmi}}$ at $\mathrm{MMI}$ width $W_{\mathrm{mmi}}=4 \mu \mathrm{m} / 8 \mu \mathrm{m} / 12 \mu \mathrm{m}$ is $28.7 \mu \mathrm{m} / 113.0 \mu \mathrm{m} / 257.2 \mu \mathrm{m}$, respectively. The device loss of a $1 \times 1 \mathrm{MMI}$ is $2.08 \mathrm{~dB} /$ $2.92 \mathrm{~dB} / 3.87 \mathrm{~dB}$, respectively, which is very significant.

\section{Linear Tapered Waveguide Analysis}

When the divergence angle of a linear tapered waveguide is set at $\theta=1^{\circ}$ with a width $W_{\mathrm{t}}$ of $4.2 \mu \mathrm{m}$ and a length $L_{\mathrm{t}}$ of $217.7 \mu \mathrm{m}$ as an experimental standard result from reference 6 , this pair of tapered waveguide loss of almost 0.004 $(0.018 \mathrm{~dB})$ can be ignored. This linear tapered waveguide with a divergence angle of $1^{\circ}$ is combined with the three different widths of $1 \times 1 \mathrm{MMI} W_{\mathrm{mmi}}$ of $4 \mu \mathrm{m} / 8 \mu \mathrm{m} / 12 \mu \mathrm{m}$ with respect to the exact imaging lengths $L_{\mathrm{mmi}}$ of $28.7 \mu \mathrm{m} /$ $113.0 \mu \mathrm{m} / 257.2 \mu \mathrm{m}$. When the ratio of $W_{\mathrm{t}} / W_{\mathrm{mmi}}$ is increased from 0.1 to 1 at a step of 0.05 , the range of the output power increases from 0.68 to 1 , as shown in Figure 4 . The output power of a $1 \times 1 \mathrm{MMI}$ combined with the linear tapered waveguide is necessary to be above 0.95 as the ratio of $W_{\mathrm{t}} /$ $W_{\text {mmi }}$ is set to above 0.35 .

Figure 5 shows the effective refractive index $n_{\text {eff }}$ for eight TE eigenmodes, including $\mathrm{TE}_{0}, \mathrm{TE}_{1}, \mathrm{TE}_{2}, \mathrm{TE}_{3}, \mathrm{TE}_{4}, \mathrm{TE}_{5}, \mathrm{TE}_{6}$, and $\mathrm{TE}_{7}$ distributed with the width of a linear tapered 


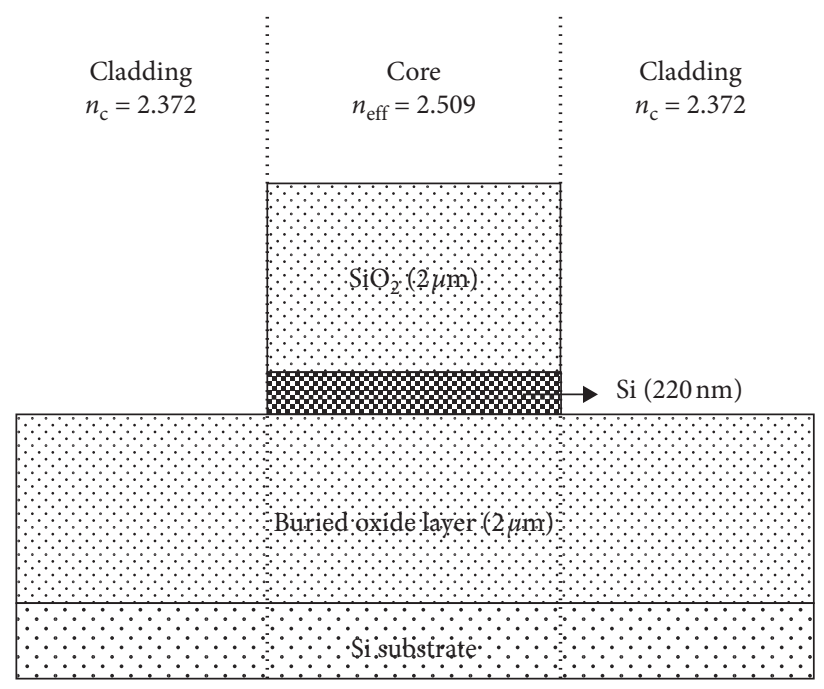

Figure 1: Schematic diagram showing the cross section of a ridge waveguide on an SOI structure.

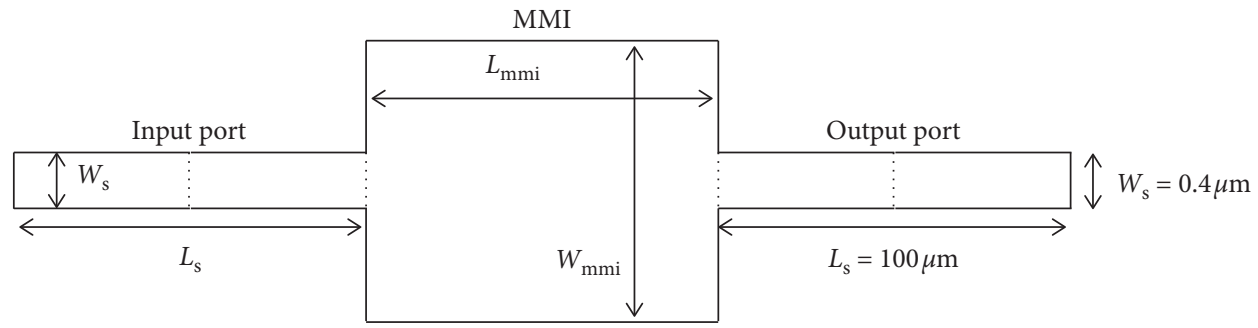

(a)

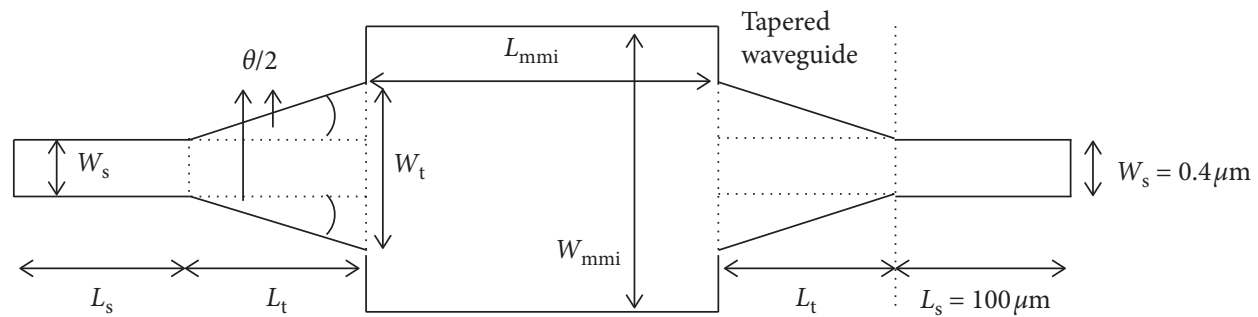

(b)

Figure 2: (a) A basic $1 \times 1 \mathrm{MMI}$ combined with the input/output single-mode waveguide for width $W_{\mathrm{s}}=0.4 \mu \mathrm{m}$ and length $L_{\mathrm{s}}=100 \mu \mathrm{m}$. (b) A linear tapered waveguide is inserted between the single-mode waveguide and MMI coupler. Width $W_{\mathrm{t}}$, length $L_{\mathrm{t}}$, and divergence angle $\theta$ describe the linear tapered waveguide.

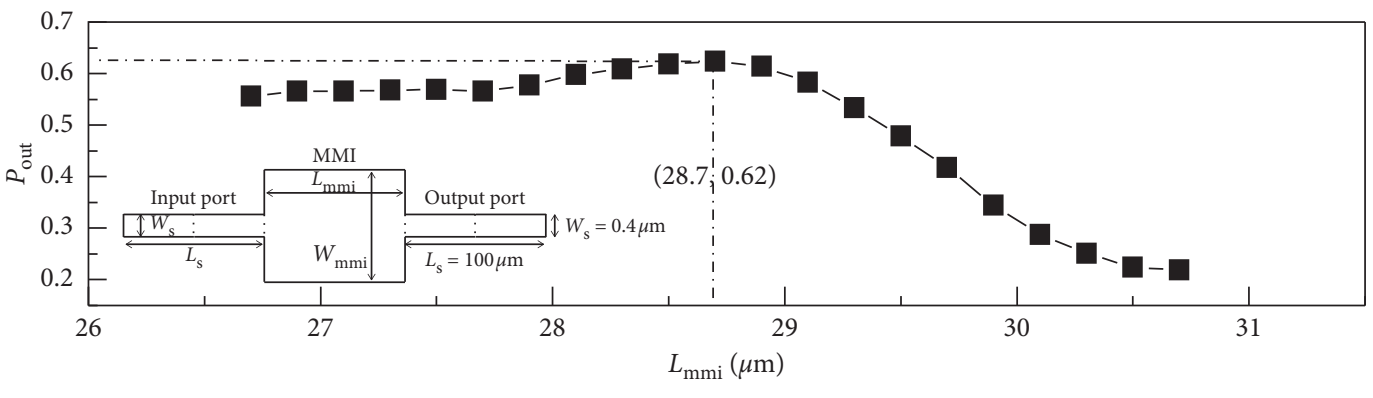

-w- $W_{\mathrm{mmi}}=4 \mu \mathrm{m}$

(a)

Figure 3: Continued. 


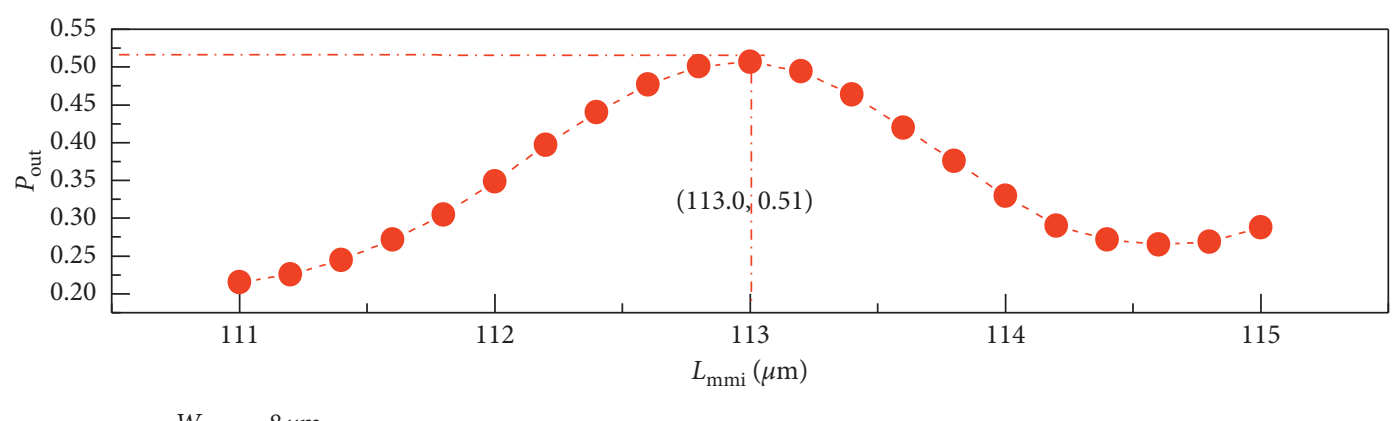

(b)

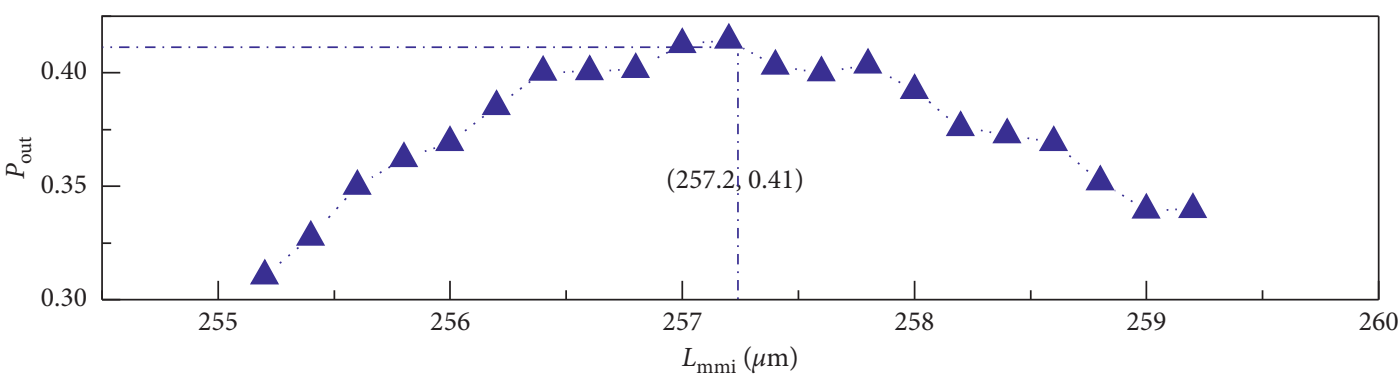

^. $W_{\mathrm{mmi}}=12 \mu \mathrm{m}$

(c)

Figure 3: (a) The maximum output power is 0.62 at MMI length $L_{\mathrm{mmi}}=28.7 \mu \mathrm{m}$ with a $1 \times 1 \mathrm{MMI}$ width $W_{\mathrm{mmi}}=4 \mu \mathrm{m}$. (b) Maximum output power is 0.51 at $L_{\mathrm{mmi}}=113.0 \mu \mathrm{m}$ and $W_{\mathrm{mmi}}=8 \mu \mathrm{m}$. (c) Maximum output power is 0.41 at $L_{\mathrm{mmi}}=257.2 \mu \mathrm{m}$ and $W_{\mathrm{mmi}}=12 \mu \mathrm{m}$.

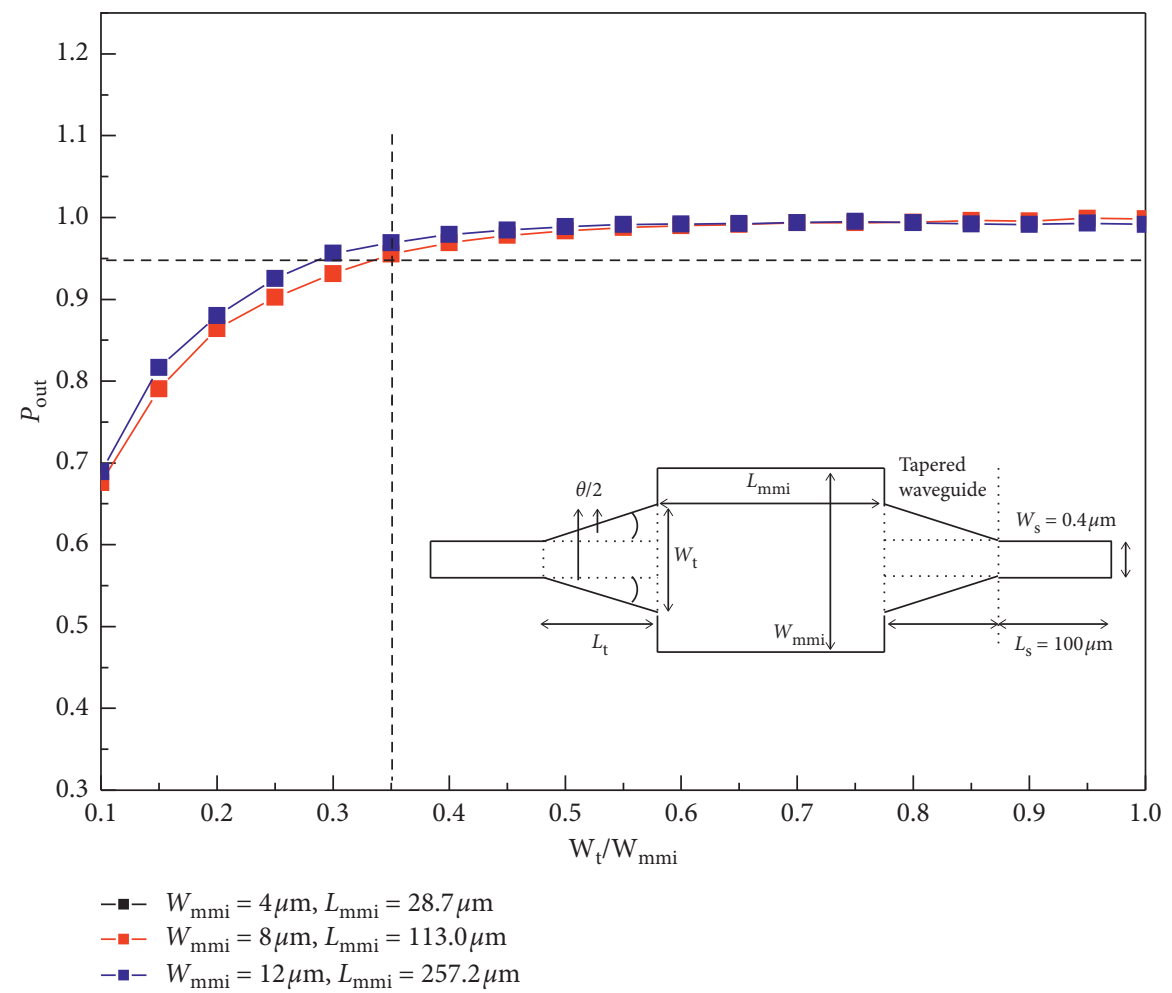

FIGURE 4: This linear tapered waveguide with a divergence angle of $1^{\circ}$ is combined with the three different widths of a $1 \times 1$ MMI coupler $W_{\mathrm{mmi}}$ of $4 \mu \mathrm{m} / 8 \mu \mathrm{m} / 12 \mu \mathrm{m}$ with respect to the exact imaging lengths $L_{\mathrm{mmi}}$ of $28.7 \mu \mathrm{m} / 113.0 \mu \mathrm{m} / 257.2 \mu \mathrm{m}$. When $W_{\mathrm{t}} / W_{\mathrm{mmi}}$ is set at above 0.35 , the output power $P_{\text {out }}$ of a $1 \times 1$ MMI coupler combined with a linear tapered waveguide achieves above 0.95 . 


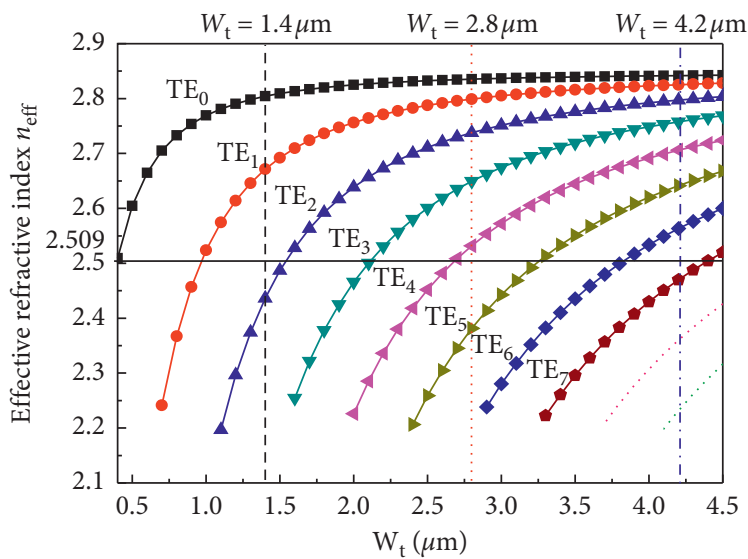

FIgURE 5: The effective refractive index of the distributed state of eight TE modes with the width of a linear tapered waveguide is ranging from $0.4 \mu \mathrm{m}$ to $4.5 \mu \mathrm{m}$. The effective refractive index $n_{\mathrm{eff}}$ of the slab waveguide on an SOI chip is 2.509 and the thickness of this linear tapered waveguide $h_{\text {co }}$ is $220 \mathrm{~nm}$ at an operating wavelength of $1550 \mathrm{~nm}$.

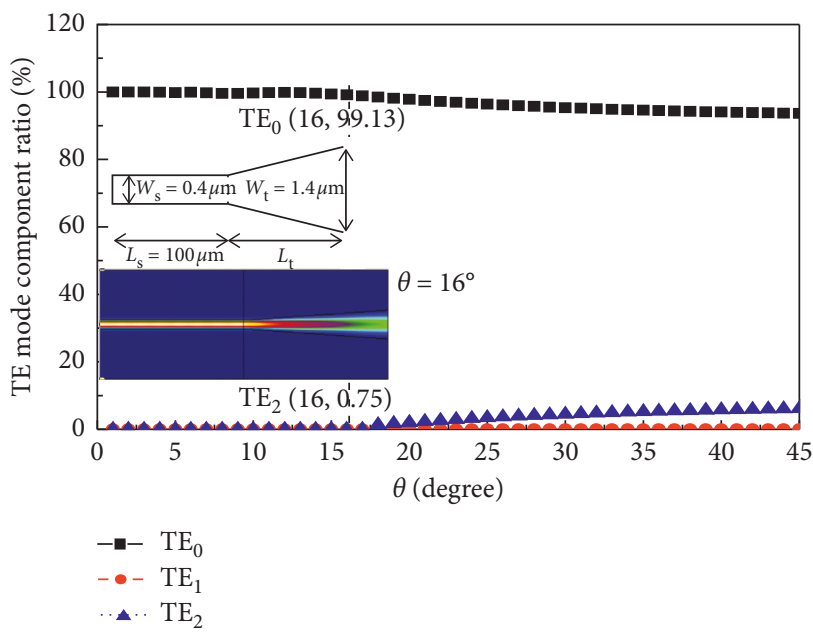

(a)

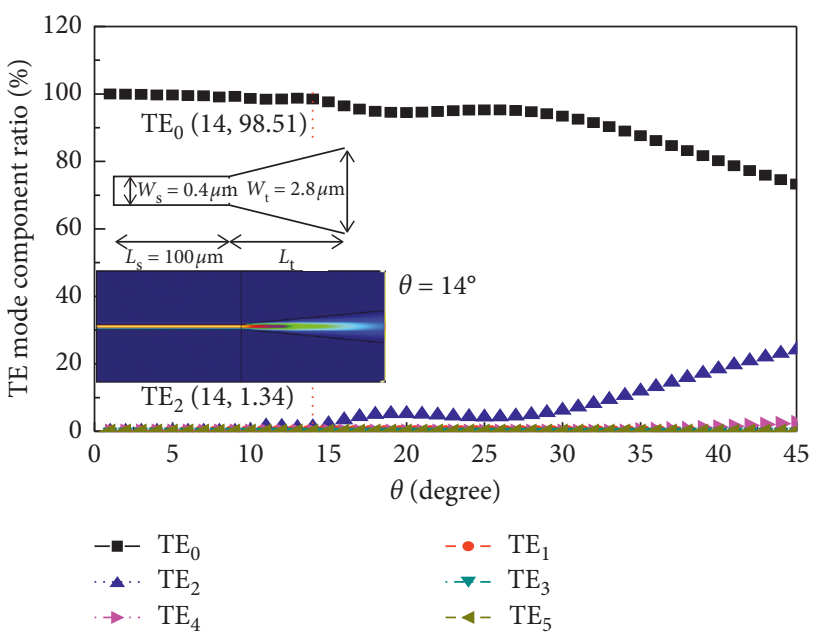

(b)

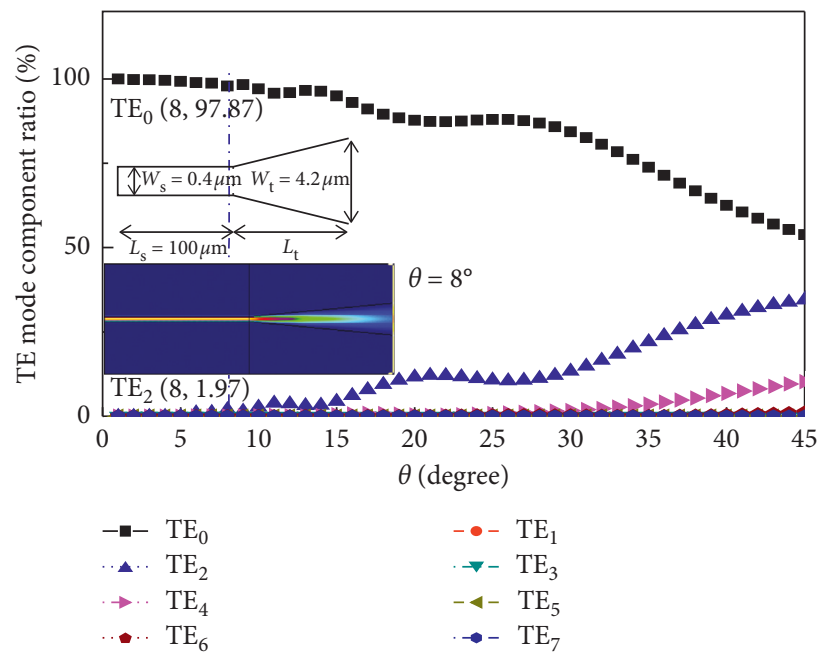

(c)

Figure 6: The width of a linear tapered waveguide (a) $W_{\mathrm{t}}=1.4 \mu \mathrm{m}, W_{\mathrm{mmi}}=4 \mu \mathrm{m}$; (b) $W_{\mathrm{t}}=2.8 \mu \mathrm{m}, W_{\mathrm{mmi}}=8 \mu \mathrm{m}$; $(\mathrm{c}) W_{\mathrm{t}}=4.2 \mu \mathrm{m}$, $W_{\mathrm{mmi}}=12 \mu \mathrm{m}$; with divergence angle $\theta$ of a linear tapered waveguide ranging from $1^{\circ}$ to $45^{\circ}$. The maximum divergence angle for linear tapered waveguide is achieved at $\theta=16^{\circ} / 14^{\circ} / 8^{\circ}$ for $W_{\mathrm{t}}=1.4 \mu \mathrm{m} / 2.8 \mu \mathrm{m} / 4.2 \mu \mathrm{m}$, respectively. 


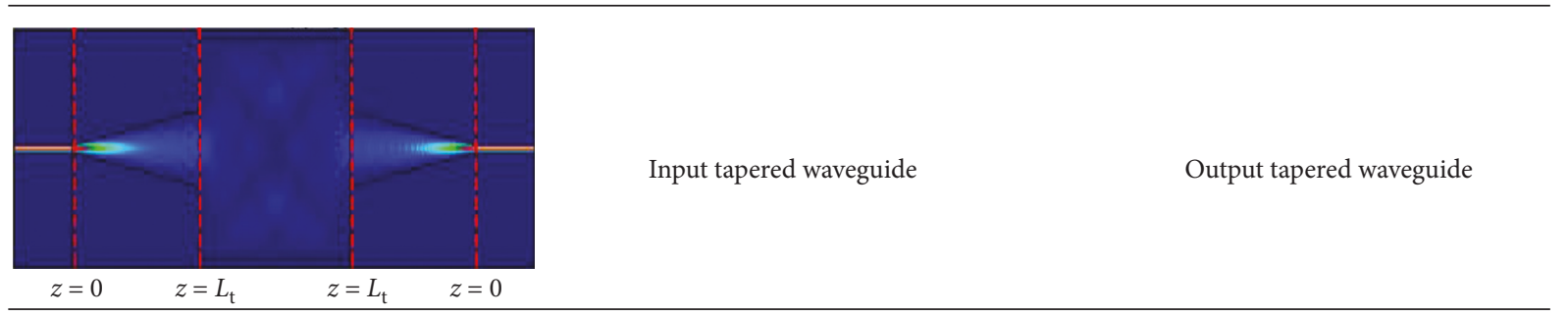

$z / L_{\mathrm{t}}=0$

$z / L_{\mathrm{t}}=0.25$
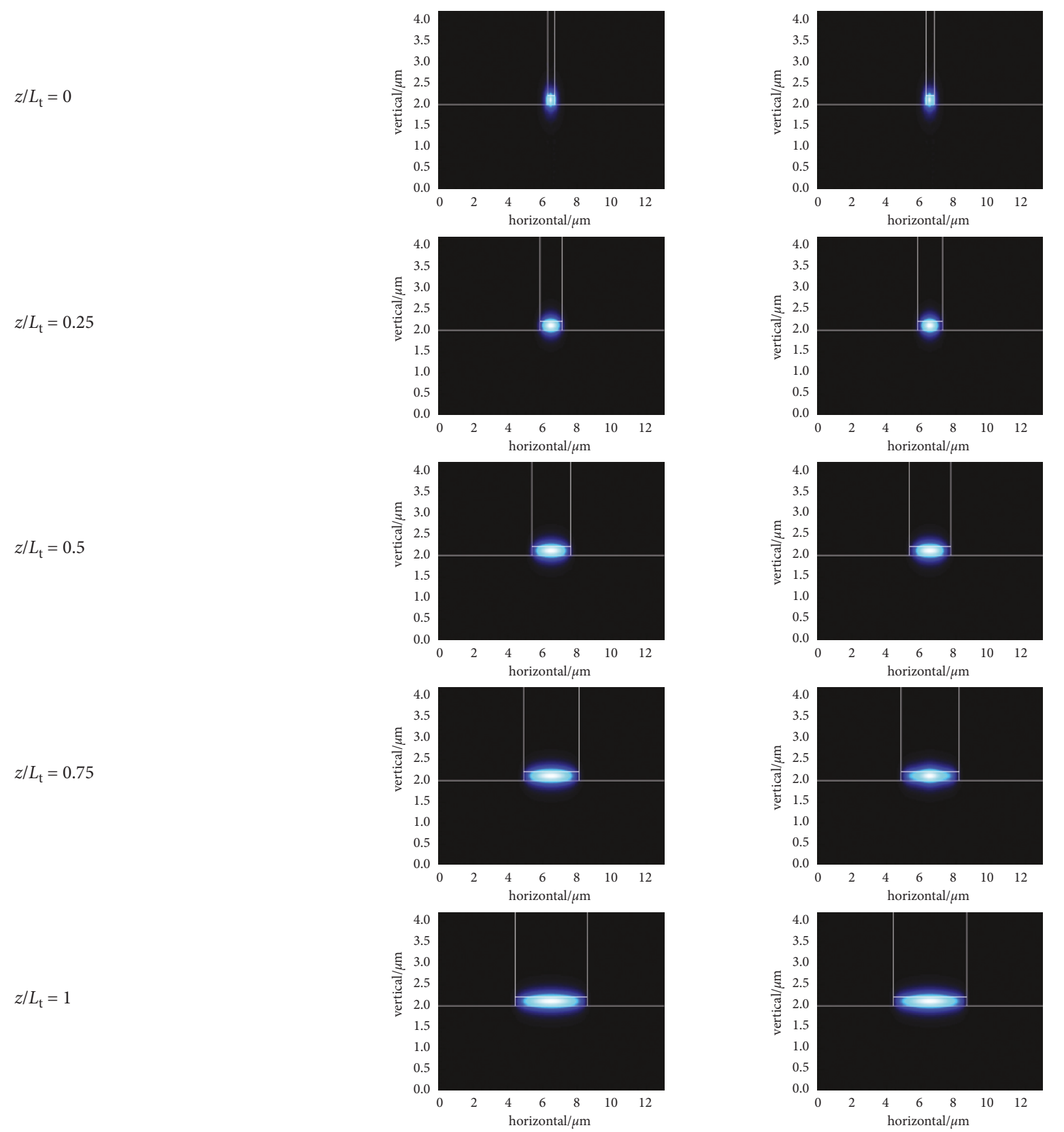

Figure 7: A $1 \times 1 \mathrm{MMI}$ in width of $12 \mu \mathrm{m}$ and in length of $257.2 \mu \mathrm{m}$ is combined with the linear tapered waveguide in width $W_{\mathrm{t}}$ of $4.2 \mu \mathrm{m}$ and in length $L_{\mathrm{t}}$ of $217.7 \mu \mathrm{m}$. When the location of input/output linear tapered waveguide is $\mathrm{z} / L_{\mathrm{t}}$ of $0 / 0.25 / 0.5 / 0.75 / 1$, the fundamental mode TE shape of input/output port is simulated to change the mode shape size from small to larger mode shape under $\mathrm{TE}_{0}$ adiabatic mode conversion.

waveguide from $0.4 \mu \mathrm{m}$ to $4.5 \mu \mathrm{m}$. As the effective refractive index $n_{\text {eff }}$ of a slab waveguide on an SOI chip is 2.509 , the eight TE eigenmodes, including $\mathrm{TE}_{0}$ to $\mathrm{TE}_{7}$, correspond to the widths of the linear tapered waveguide $W_{\mathrm{t}}$. Three different widths of $1 \times 1 \mathrm{MMI} W_{\mathrm{mmi}}$ of $4 \mu \mathrm{m} / 8 \mu \mathrm{m} / 12 \mu \mathrm{m}$ obtain a minimum width for a linear tapered waveguide $W_{\mathrm{t}}$ of $1.4 \mu \mathrm{m} /$ 


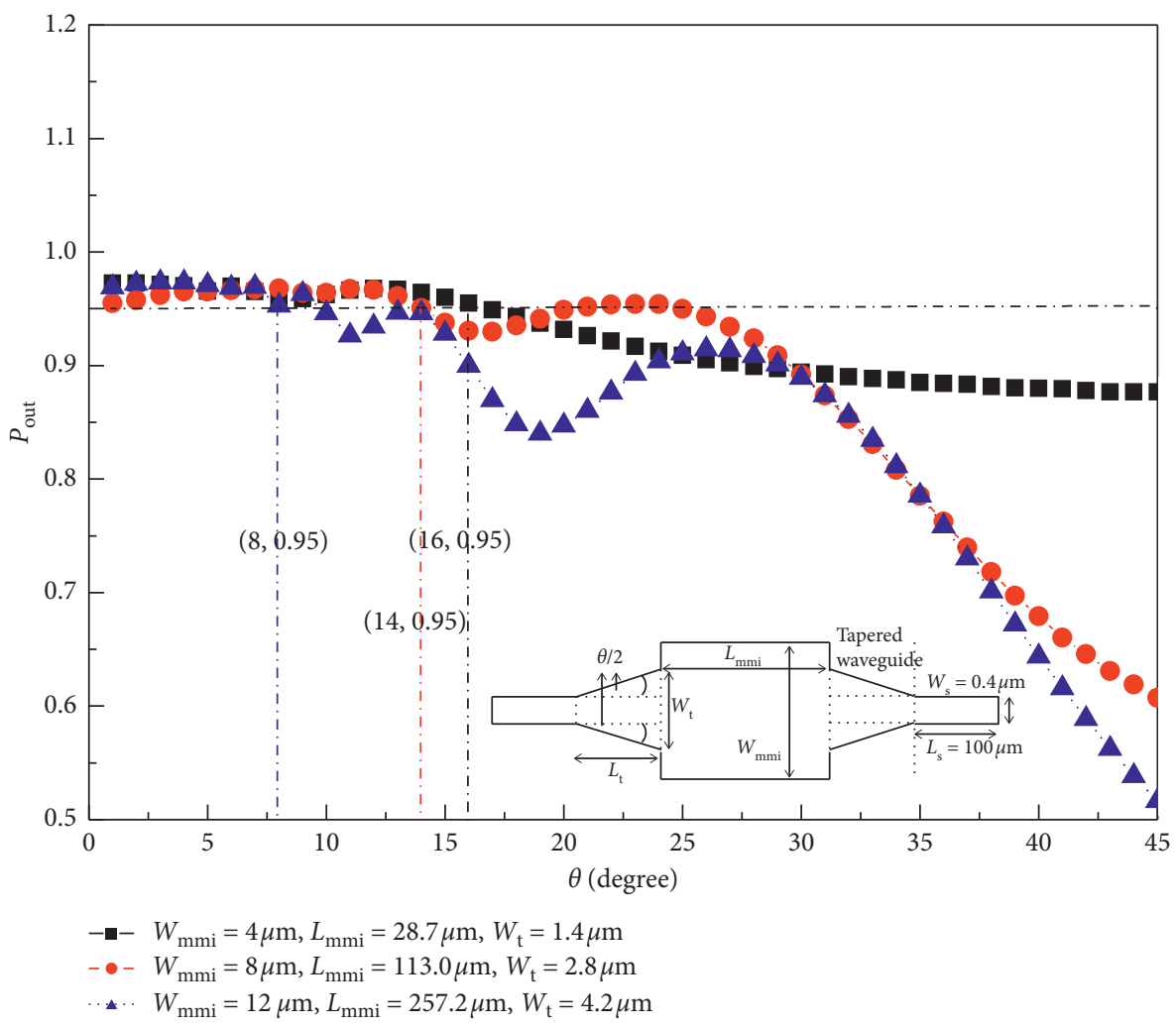

FIGURE 8: When $W_{\mathrm{t}} / W_{\mathrm{mmi}}$ is set at 0.35 , the $1 \times 1 \mathrm{MMI}$ coupler with $W_{\mathrm{mmi}}=4 \mu \mathrm{m} / 8 \mu \mathrm{m} / 12 \mu \mathrm{m}$ achieves a minimum width of linear tapered waveguide at $W_{\mathrm{t}}=1.4 \mu \mathrm{m} / 2.8 \mu \mathrm{m} / 4.2 \mu \mathrm{m}$, respectively. As the divergence angle $\theta$ of a linear tapered waveguide is scanning the range from $1^{\circ}$ to $45^{\circ}$ at a step of $1^{\circ}$, a maximum divergence angle $\theta=16^{\circ} / 14^{\circ} / 8^{\circ}$ is obtained under the constraint of $P_{\text {out }} \geq 0.95$, respectively.

$2.8 \mu \mathrm{m} / 4.2 \mu \mathrm{m}$, respectively. As the $\mathrm{TE}_{0}$ mode is transmitted from a single-mode waveguide with a width of $0.4 \mu \mathrm{m}$ into a linear tapered waveguide with a width $W_{\mathrm{t}}$ of $1.4 \mu \mathrm{m}, \mathrm{TE}_{0}$ and $\mathrm{TE}_{1}$ are excited. The taper width $W_{\mathrm{t}}$ of $2.8 \mu \mathrm{m}$ is excited for $\mathrm{TE}_{0}, \mathrm{TE}_{1}, \mathrm{TE}_{2}, \mathrm{TE}_{3}$, and $\mathrm{TE}_{4}$ modes. The taper width $W_{\mathrm{t}}$ of $4.2 \mu \mathrm{m}$ is excited for $\mathrm{TE}_{0}, \mathrm{TE}_{1}, \mathrm{TE}_{2}, \mathrm{TE}_{3}, \mathrm{TE}_{4}, \mathrm{TE}_{5}$, and $\mathrm{TE}_{6}$ modes. As the geometric shape of the device is symmetrical structure, the odd modes are suppressed and inexistent.

The single-mode waveguide with width $W_{\mathrm{s}}$ of $0.4 \mu \mathrm{m}$ is combined with the width of the linear tapered waveguide $W_{\mathrm{t}}$ of $1.4 \mu \mathrm{m} / 2.8 \mu \mathrm{m} / 4.2 \mu \mathrm{m}$, respectively. TE mode component ratio is distributed with the divergence angle of a linear tapered waveguide ranging from $1^{\circ}$ to $45^{\circ}$, as shown in Figure 6. When the even modes of $\mathrm{TE}_{2}, \mathrm{TE}_{4}$, and $\mathrm{TE}_{6}$ and the odd modes of $\mathrm{TE}_{1}, \mathrm{TE}_{3}, \mathrm{TE}_{5}$, and $\mathrm{TE}_{7}$ except $\mathrm{TE}_{0}$ are suppressed in the linear tapered waveguide, the maximum divergence angle $\theta$ of the linear tapered waveguide is $16^{\circ} / 14^{\circ} \%$ $8^{\circ}$ with respect to a $1 \times 1 \mathrm{MMI}$ with width $W_{\mathrm{mmi}}$ of $4 \mu \mathrm{m} /$ $8 \mu \mathrm{m} / 12 \mu \mathrm{m}$. The $\mathrm{TE}_{0}$ mode component ratio obtains individual $99.13 \% / 98.51 \% / 97.87 \%$. So, this linear tapered waveguide achieves the $\mathrm{TE}_{0}$ mode adiabatic mode conversion when the $\mathrm{TE}_{0}$ mode component ratio is at least $97.87 \%$ and $\mathrm{TE}_{2}$ mode and the other modes component ratio is below $2.13 \%$.

For a standard adiabatic mode conversion analysis, a $1 \times 1 \mathrm{MMI}$ in width of $12 \mu \mathrm{m}$ and in length of $257.2 \mu \mathrm{m}$ is combined with the divergence angle $\theta=1^{\circ}$ of linear tapered waveguide in width $W_{\mathrm{t}}$ of $4.2 \mu \mathrm{m}$ and in length $L_{\mathrm{t}}$ of
$217.7 \mu \mathrm{m}$. When the location of input/output linear tapered waveguide is $z / L_{\mathrm{t}}$ of $0 / 0.25 / 0.5 / 0.75 / 1$, the fundamental mode $\mathrm{TE}_{0}$ shape of input/output port is simulated to change the mode shape size from smaller to larger mode shape under $\mathrm{TE}_{0}$ adiabatic mode conversion as shown in Figure 7. The coupling efficiency of this device between the singlemode waveguide and the multimode waveguide is enhanced from 0.41 to 0.95 .

The $1 \times 1$ MMI with width $W_{\mathrm{mmi}}$ of $4 \mu \mathrm{m} / 8 \mu \mathrm{m} / 12 \mu \mathrm{m}$ is combined with the width of the linear tapered waveguide $W_{\mathrm{t}}$ of $1.4 \mu \mathrm{m} / 2.8 \mu \mathrm{m} / 4.2 \mu \mathrm{m}$, respectively, as the input and output port with the divergence angle $\theta$ of a linear tapered waveguide scanning the range from $1^{\circ}$ to $45^{\circ}$ at a step of $1^{\circ}$. The maximum divergence angle $\theta$ is achieved at $16^{\circ} / 14^{\circ} / 8^{\circ}$, respectively, under the condition of output power of a $1 \times 1 \mathrm{MMI}$ combined with a linear tapered waveguide of at least 0.95 , as shown in Figure 8. Figure 9 shows that the spectral responses are insensitivity for the wavelength from 1546 to $1554 \mathrm{~nm}$ with the step of $1 \mathrm{~nm}$ under the condition of this linear tapered waveguide with a maximum divergence angle $\theta$ of $16^{\circ} / 14^{\circ} / 8^{\circ}$ combined with the three different widths of a $1 \times 1$ MMI of $4 \mu \mathrm{m} / 8 \mu \mathrm{m} / 12 \mu \mathrm{m}$, respectively. The output power of three different widths of a $1 \times 1$ MMI linked with the maximum divergence angle $\theta$ of $16^{\circ} / 14^{\circ} / 8^{\circ}$ of a linear tapered waveguide is 0.95 when the ratio of $W_{\mathrm{t}} / W_{\mathrm{mmi}}$ is equal to 0.35 . Three different divergence angles $\theta$ of the linear tapered waveguide of $16^{\circ} / 14^{\circ} / 8^{\circ}$ with respect to three different widths of a $1 \times 1 \mathrm{MMI}$ width $W_{\text {mmi }}$ of $4 \mu \mathrm{m} / 8 \mu \mathrm{m} / 12 \mu \mathrm{m}$ are taken into equation (4). 


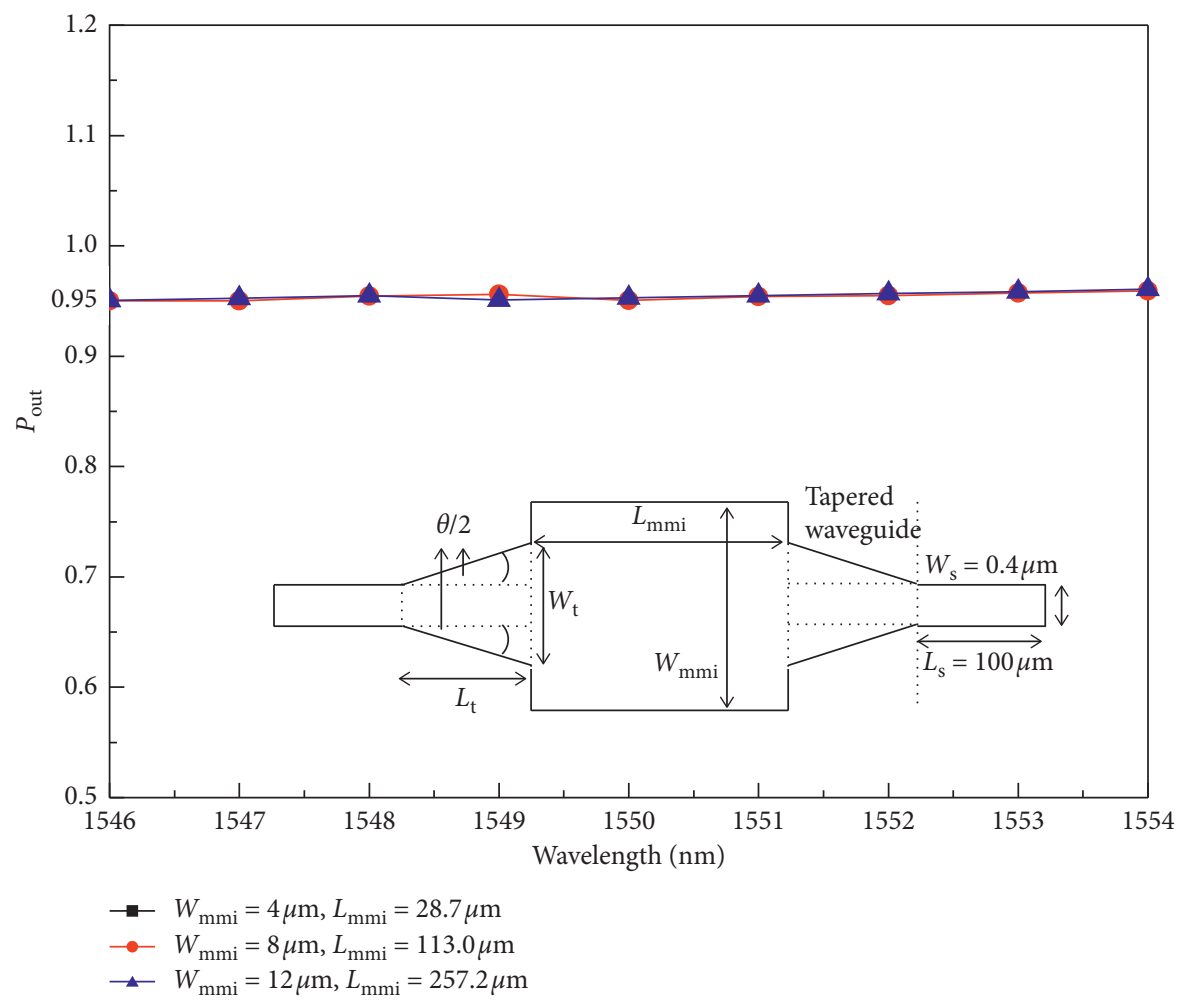

FIGURE 9: The spectral responses are insensitivity for the wavelength from 1546 to $1554 \mathrm{~nm}$ with the step of $1 \mathrm{~nm}$ under the condition of this linear tapered waveguide with a maximum divergence angle $\theta$ of $16^{\circ} / 14^{\circ} / 8^{\circ}$ combined with the three different widths of a $1 \times 1 \mathrm{MMI}$ of $4 \mu \mathrm{m} /$ $8 \mu \mathrm{m} / 12 \mu \mathrm{m}$, respectively.

TABLE 1: A basic $1 \times 1$ MMI device loss.

\begin{tabular}{lcr}
\hline$W_{\mathrm{mmi}}(\mu \mathrm{m})$ & $L_{\mathrm{mmi}}(\mu \mathrm{m})$ & Pout $($ device loss $(\mathrm{dB}))$ \\
\hline 4 & 28.7 & $0.62(2.08 \mathrm{~dB})$ \\
8 & 113.0 & $0.51(2.92 \mathrm{~dB})$ \\
12 & 257.2 & $0.41(3.87 \mathrm{~dB})$ \\
\hline
\end{tabular}

The length of a linear tapered waveguide $L_{\mathrm{t}}$ is calculated by $3.6 \mu \mathrm{m} / 9.8 \mu \mathrm{m} / 27.2 \mu \mathrm{m}$, respectively. The ratio of the length of a linear tapered waveguide to the length of a $1 \times 1 \mathrm{MMI}$ is expressed as $L_{\mathrm{t}} / L_{\mathrm{mmi}} \geqq 0.086$.

The expressions of equations (5) and (6) are demonstrated under three different widths of a $1 \times 1 \mathrm{MMI}$ coupler combined with a designed linear tapered waveguide:

$$
\begin{aligned}
& W_{\mathrm{t}} \geq 0.35 W_{\mathrm{mmi}}, \\
& L_{\mathrm{t}} \geq 0.086 L_{\mathrm{mmi}},
\end{aligned}
$$

where $W_{\mathrm{t}}$ is the width of the linear tapered waveguide, $L_{\mathrm{t}}$ is the length of the linear tapered waveguide, and $W_{\mathrm{mmi}}$ is the width of a $1 \times 1 \mathrm{MMI}$ and $L_{\mathrm{mmi}}$ of the exact imaging length of a $1 \times 1$ MMI. When the width of the single-mode waveguide $W_{\mathrm{s}}$ of $0.4 \mu \mathrm{m}$ and equations (5) and (6) are taken into equation (4), the maximum divergence angle, $\theta$, is expressed as equation (7).

$$
\theta \leq 2 \tan ^{-1}\left(\frac{0.35 W_{\mathrm{mmi}}-W_{\mathrm{s}}}{0.172 L_{\mathrm{mmi}}}\right) .
$$

Comparison of basic $1 \times 1$ MMI device loss with a $1 \times 1$ MMI combined with a linear tapered waveguide device loss is shown in Tables 1 and 2 . When $1 \times 1 \mathrm{MMI}$ with width $W_{\mathrm{mmi}}$ of $4 \mu \mathrm{m} / 8 \mu \mathrm{m} / 12 \mu \mathrm{m}$ is combined with a maximum divergence angle $\theta=16^{\circ} / 14^{\circ} / 8^{\circ}$ in a linear tapered waveguide with a width $W_{\mathrm{t}}$ of $1.4 \mu \mathrm{m} / 2.8 \mu \mathrm{m} / 4.2 \mu \mathrm{m}$ and length $L_{\mathrm{t}}$ of $3.6 \mu \mathrm{m} / 9.8 \mu \mathrm{m} / 27.2 \mu \mathrm{m}$, the loss of this linear tapered waveguide is $0.022 \mathrm{~dB} / 0.172 \mathrm{~dB} / 0.158 \mathrm{~dB}$. The length of a maximum divergence angle $\theta=16^{\circ} / 14^{\circ} / 8^{\circ}$ in this linear tapered waveguide is reduced to $93.7 \% / 92.9 \% / 87.5 \%$ than the length of the divergence angle $\theta=1^{\circ}$ combined a $1 \times 1 \mathrm{MMI}$ with width of $4 \mu \mathrm{m} / 8 \mu \mathrm{m} / 12 \mu \mathrm{m}$. The output power of a $1 \times 1$ MMI combined with the maximum divergence angle of a linear tapered waveguide is $0.95(0.22 \mathrm{~dB})$. A $1 \times 1 \mathrm{MMI}$ device loss with a linear tapered waveguide reduces $1.86 \mathrm{~dB} /$ $2.70 \mathrm{~dB} / 3.65 \mathrm{~dB}$ than a $1 \times 1 \mathrm{MMI}$ device loss without a linear 
TABLE 2: A $1 \times 1$ MMI combined with a linear tapered waveguide device loss.

\begin{tabular}{lccc}
\hline Pout $($ Device loss $(\mathrm{dB}))$ & $W_{\mathrm{t}}(\mu \mathrm{m})$ & Max. divergence angle (degree) & Linear tapered waveguide loss $(\mathrm{dB})$ \\
\hline $0.95(0.22 \mathrm{~dB})$ & 1.4 & $16^{\circ}$ & 0.022 \\
$0.95(0.22 \mathrm{~dB})$ & 2.8 & $14^{\circ}$ & 0.172 \\
$0.95(0.22 \mathrm{~dB})$ & 4.2 & $8^{\circ}$ & 0.158 \\
\hline
\end{tabular}

tapered waveguide. This device loss represents a significant reduction.

\section{Conclusion}

A $1 \times 1 \mathrm{MMI}$ is combined with a symmetrical linear tapered waveguide on an SOI chip. When $\mathrm{TE}_{0}$ mode from a single-mode waveguide is transmitted to this critical linear tapered waveguide linked with a $1 \times 1 \mathrm{MMI}$, the $\mathrm{TE}_{0}$ mode component ratio is necessary to be at least $97.87 \%$ and the $\mathrm{TE}_{2}$ mode and the other modes' component ratios are to be below $2.13 \%$. So, the $\mathrm{TE}_{0}$ mode presents a critical adiabatic mode conversion. The designed linear tapered waveguide is achieved to the shortest length and the maximum divergence angle.

Under the condition of a $1 \times 1 \mathrm{MMI}$ coupler combined with the designed linear tapered waveguide, the maximum divergence angle is demonstrated by $\theta \leq 2 \tan ^{-1}$ $\left[\left(0.35 W_{\mathrm{mmi}}-W_{\mathrm{s}}\right) /\left(0.172 L_{\mathrm{mmi}}\right)\right]$. When the width of a $1 \times 1$ MMI $W_{\mathrm{mmi}}$ is $4 \mu \mathrm{m} / 8 \mu \mathrm{m} / 12 \mu \mathrm{m}$ with respect to the length $L_{\mathrm{mmi}}$ of $28.7 \mu \mathrm{m} / 113.0 \mu \mathrm{m} / 257.2 \mu \mathrm{m}$, the maximum divergence angle $\theta$ is achieved to $16^{\circ} / 14^{\circ} / 8^{\circ}$, respectively.

A $1 \times 1$ MMI width $W_{\mathrm{mmi}}$ of $4 \mu \mathrm{m} / 8 \mu \mathrm{m} / 12 \mu \mathrm{m}$ combined with a maximum divergence angle $\theta=16^{\circ} / 14^{\circ} / 8^{\circ}$ linear tapered waveguide to a $1 \times 1 \mathrm{MMI}$ without linear tapered waveguide. The simulation result shows that the device loss is reduced by $1.86 \mathrm{~dB} / 2.70 \mathrm{~dB} / 3.65 \mathrm{~dB}$, respectively, with respect to an extreme linear tapered waveguide loss of $0.022 \mathrm{~dB} / 0.172 \mathrm{~dB} / 0.158 \mathrm{~dB}$. The length of a maximum divergence angle $\theta=16^{\circ} / 14^{\circ} / 8^{\circ}$ linear tapered waveguide is reduced to $93.7 \% / 92.9 \% / 87.5 \%$ than the length of the $\mathrm{di}$ vergence angle $\theta=1^{\circ}$ linear tapered waveguide combined with a $1 \times 1 \mathrm{MMI}$ with width of $4 \mu \mathrm{m} / 8 \mu \mathrm{m} / 12 \mu \mathrm{m}$. The output power of a $1 \times 1 \mathrm{MMI}$ combined with a critical linear tapered waveguide is at least 0.95 , which enhanced the coupling efficiency by 1.5 times.

\section{Data Availability}

The data used to support the findings of this study are included within the article files.

\section{Conflicts of Interest}

The authors declare that they have no conflicts of interest.

\section{Acknowledgments}

This work was supported in part by the Ministry of Science and Technology, Taiwan, Republic of China, under the grant no. MOST 108-2221-E-992-080.

\section{References}

[1] R. Soref, "The past, present, and future of silicon photonics," IEEE Journal of Selected Topics in Quantum Electronics, vol. 12, no. 6, pp. 1678-1687, 2006.

[2] M. Lipson, "Guiding, modulating, and emitting light on silicon-challenges and opportunities," Journal of Lightwave Technology, vol. 23, no. 12, pp. 4222-4238, 2005.

[3] K. Kruse and C. T. Middlebrook, "Polymer taper bridge for silicon waveguide to single mode waveguide coupling," Optics Communications, vol. 362, pp. 87-95, 2016.

[4] J. Guo and Y. Zhao, "Analysis of mode hybridization in tapered waveguides," IEEE Photonics Technology Letters, vol. 27, no. 23, pp. 2441-2444, 2015.

[5] D. J. Thomson, Y. Hu, G. T. Reed, and J.-M. Fedeli, "Low loss MMI couplers for high performance MZI modulators," IEEE Photonics Technology Letters, vol. 22, no. 20, pp. 1485-1487, 2010.

[6] Z. Sheng, Z. Zhiqi Wang, C. Chao Qiu et al., "A compact and low-loss MMI coupler fabricated with CMOS technology," IEEE Photonics Journal, vol. 4, no. 6, pp. 2272-2277, 2012.

[7] P. Sethi, A. Haldar, and S. K. Selvaraja, "Ultra-compact lowloss broadband waveguide taper in silicon-on-insulator," Optics Express, vol. 25, no. 9, pp. 10196-10203, 2017.

[8] Y. Liu, W. Sun, H. Xie et al., "Adiabatic and ultra-compact waveguide tapers based on digital metamaterials," IEEE Journal of Selected Topics in Quantum Electronics, vol. 25, no. 3, pp. 1-6, 2018.

[9] J. Zhang, J. Yang, H. Xin, J. Huang, D. Chen, and Z. Zhaojian, "Ultrashort and efficient adiabatic waveguide taper based on thin flat focusing lenses," Optics Express, vol. 25, no. 17, pp. 19894-19903, 2017.

[10] Y. Fu, T. Ye, W. Tang, and T. Chu, "Efficient adiabatic siliconon-insulator waveguide taper," Photonics Research, vol. 2, no. 3, pp. A41-A44, 2014.

[11] J. Wang, M. Qi, Y. Xuan et al., "Proposal for fabricationtolerant SOI polarization splitter-rotator based on cascaded MMI couplers and an assisted bi-level taper," Optics Express, vol. 22, no. 23, pp. 27869-27879, 2014.

[12] Y. Zhang, S. Yang, A. E.-J. Lim et al., "A CMOS-compatible, low-loss, and low-crosstalk silicon waveguide crossing," IEEE Photonics Technology Letters, vol. 25, no. 5, pp. 422-425, 2013.

[13] D. Dai, Y. Tang, and J. E. Bowers, "Mode conversion in tapered submicron silicon ridge optical waveguides," Optics Express, vol. 20, no. 12, pp. 13425-13439, 2012.

[14] L. He, Y. He, A. Pomerene et al., "Ultrathin silicon-on-insulator grating couplers," IEEE Photonics Technology Letters, vol. 24, no. 24, pp. 2247-2249, 2012.

[15] C.-H. Chen and C.-H. Chiu, "Taper-integrated multimodeinterference based waveguide crossing design," IEEE Journal of Quantum Electronics, vol. 46, no. 11, pp. 1656-1661, 2010.

[16] W. Bogaerts, P. Dumon, D. V. Thourhout, and R. Baets, "Lowloss, low-cross-talk crossings for silicon-on-insulator nanophotonic waveguides," Optics Letters, vol. 32, no. 19, pp. 2801-2803, 2007. 
[17] J. J. Wu, B. R. Shi, and M. Kong, "Exponentially tapered multimode interference couplers," Chinese Optics Letters, vol. 4, no. 3, pp. 167-169, 2006.

[18] P. K. Bhattacharya, Semiconductor Optoelectronic Devices, Prentice-Hall, Englewood Cliffs, NJ, USA, 1998.

[19] L. B. Soldano and E. C. M. Pennings, "Optical multi-mode interference devices based on self-imaging: principles and applications," Journal of Lightwave Technology, vol. 13, no. 4, pp. 615-627, 1995.

[20] M. Bachmann, P. A. Besse, and H. Melchior, "Overlappingimage multimode interference couplers with a reduced number of self-images for uniform and nonuniform power splitting," Applied Optics, vol. 34, no. 30, pp. 6898-6910, 1995.

[21] A. S. Sudbo, "Film mode matching: a versatile numerical method for vector mode field calculations in dielectric waveguides," Pure and Applied Optics: Journal of the European Optical Society Part A, vol. 2, no. 3, pp. 211-233, 1993.

[22] Integrated Optics Software FIMMWAVE 5.2, Photon Design, Oxford, U.K, 2015, http://www.photond.com. 

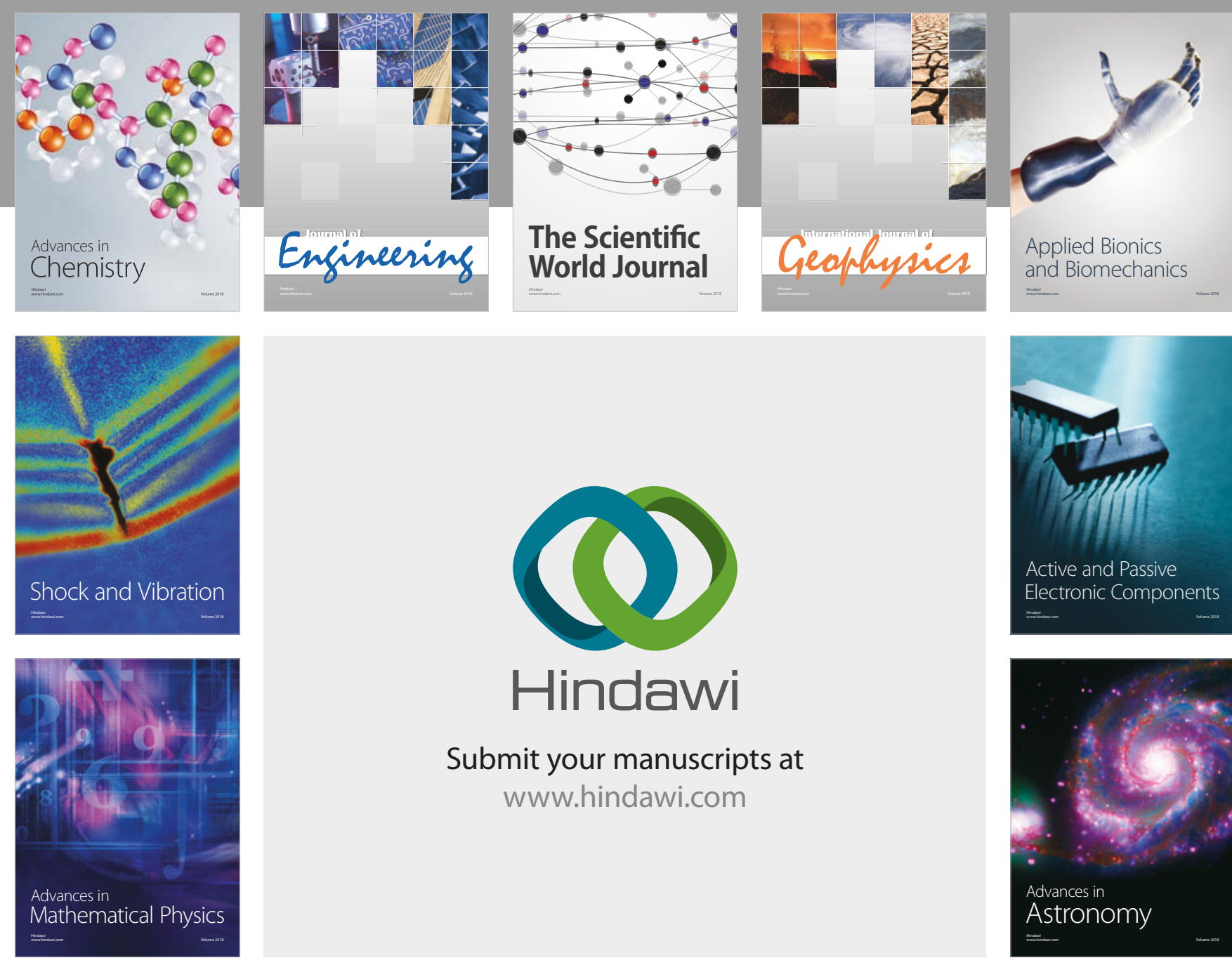

Submit your manuscripts at

www.hindawi.com

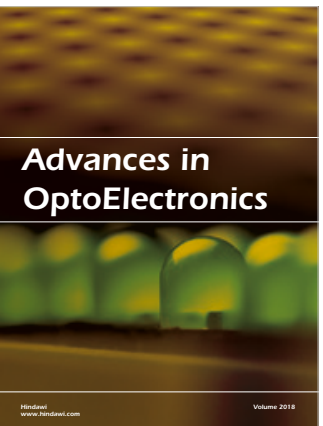

\section{Rotcting Machinery}
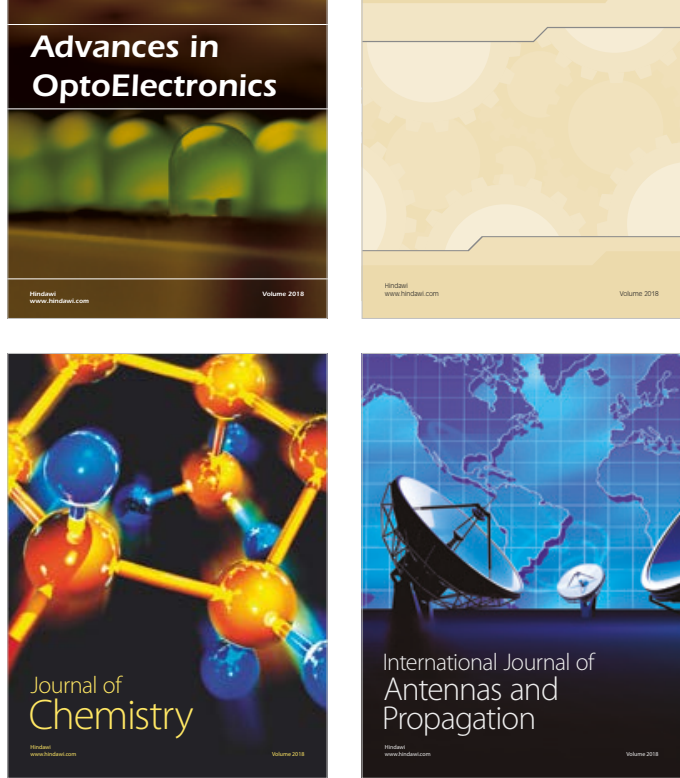

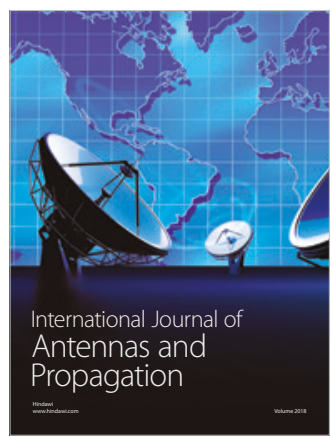

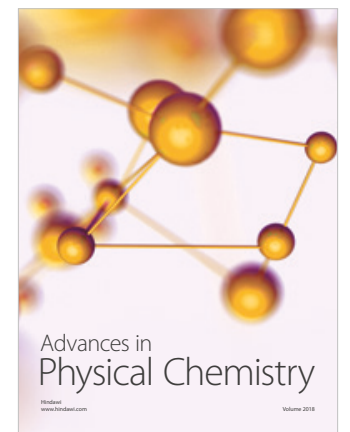

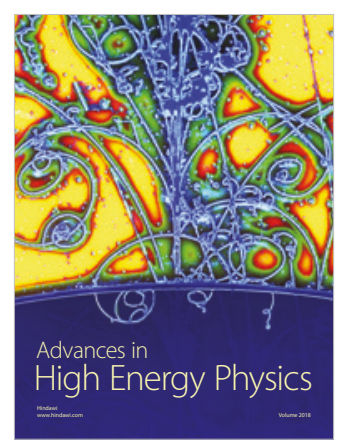

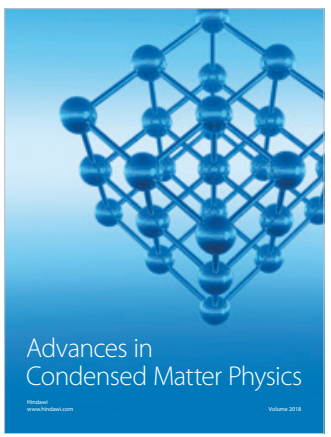

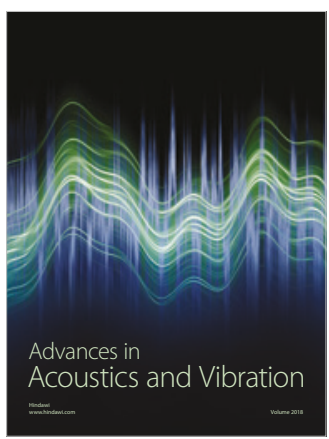

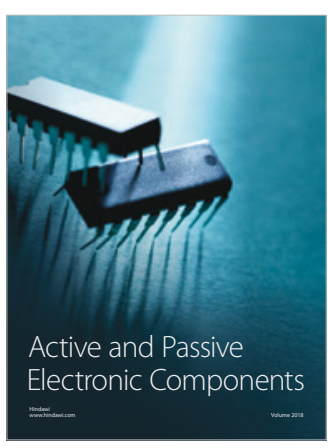
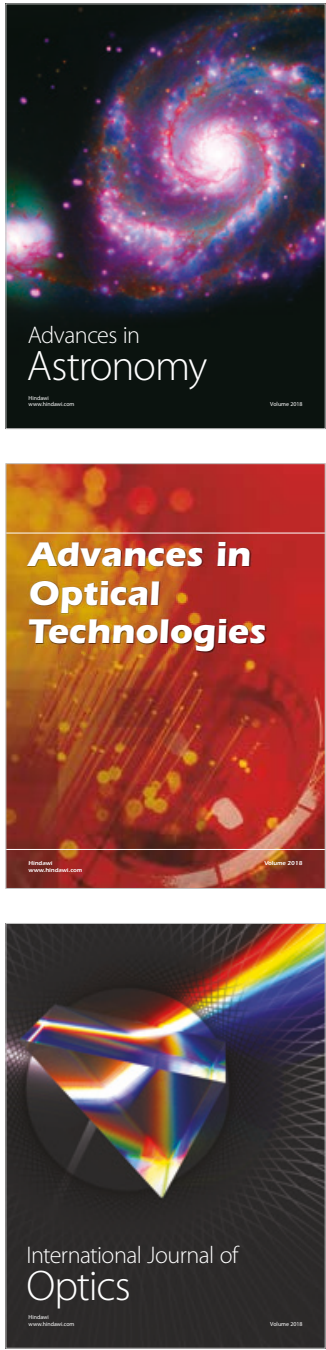